\title{
П.Н. Барышников
}

\section{ЭМЕРДЖЕНТНЫЕ СВОЙСТВА ЯЗЫКОВЫХ ПРОЦЕССОВ СОЗНАНИЯ}

\begin{abstract}
Речь идет о теоретико-методологических основаниях эмерджентизма в современной философии сознания и лингвистике. Основная цель состоит в выявлении преимуществ эмерджентных моделей в контексте нередуктивного функционализма, теории синтаксической сложности и концептуальной семантики. Мы исходим из положения, что «трудная проблема» сознания - результат специфичной онтологии языкового знака. Семантико-прагматическая природа языкового знака может рассматриваться как связующее звено между ментальными состояниями, феноменальнылм суждениями (самоаттестацичей) и ментальной каузацией.

Ключевые слова: эмерджентизм, функциональные свойства, элементарные структуры, ментальная каузация.
\end{abstract}

Tермин «emergent» (эмерджентный) в английском языке имеет несколько значений, два из которых широко применяются в научной методологии: 1) возникающий неожиданно; 2) предстающий как естественное или логическое следствие. Впервые в научном дискурсе данный термин был применен английским философом и литературным критиком Дж. Г. Льюисом. Первоначальное значение термина определялось через свойства иерархической системы, представляющей собой нечто большое, чем совокупность своих компонентов. То есть эмерджентность системы представляется как несводимость свойств множества к свойствам входящих в него подмножеств. Принцип несводимости противопоставляет эмерджентизм всем видам редукционизма.

Несмотря на известную критику, эмерджентизм привнес нетривиальные результаты как в лингвистические теории, так и в философию сознания. Данное направление выделяется на фоне субстанциального или структурнофункционального типов редукционизма, поэтому сопоставительный анализ эмерджентистских исследований в рамках лингвистки и философии сознания составляет определённый исследовательский интерес.

\section{1. Эмерджентизм в философии сознания}

Многие исследователи (Т. Нагель, Дж. Фодор, Х. Патнем), принимающие идею нередуцируемости ментального к физическому, рассматривают эмерджентные свойства материи мозга как основание для феноменального «эффекта» сознания $[1,2]$. Долгое время популярной метафорой эмерджентности выступало сравнение отношений мозга и сознания с водой и текучестью, придуманное Дж. Серлом: «Сознание есть ментальное и потому физическое свойство мозга в том смысле, в каком жидкое состояние есть свойство системы молекул» [3]. Данная метафора справедливо подверглась критике, так как свойство текучести воды есть диспозиционное свойство. Это некоторая возможность измененных состояний. К.Г. Фролов указывает также на методоло- 
гический тупик в понимании сознания, если рассматривать его как эмерджентную функцию физической системы по принципу «целое больше совокупности частей». Множество молекул воды не может быть коррелятом текучести, как множество соединений нейронов (искусственных или естественных) не может быть коррелятом сознания. В противном случае определение противоречит тезису о нередуцируемости [4. С. 79]. Если понимать физическую систему не как объект, а как эпистемологическую модель, то эмерджентность становится скорее свойством языка наблюдателя. В этом случае сознание принципиально непознаваемо, так как не способно полагать самое себя в качестве системы свойств или отношений. Этот объяснительный разрыв (известный в аналитической философии под термином «еxplanatory gap»), на наш взгляд, преодолевается, если исследовать сознание не в контексте физических процессов мозга, а в контексте семантических процессов языка. Согласно Т. Нагелю, «сознание следует признать концептуально несводимым аспектом реальности» [5].

Этот тезис, возможно, правомерен относительно физических процессов, но мы будем исходить из допущения, что сознание реализуемо в онтологии языкового знака. (Термин «реализуемо» связан с традицией функционализма. Именно через понятие функциональной реализации объяснялась психофизическая проблема в середине XX в.). При таком допущении приобретает значимость пример лингвистического антиредукционизма: «речь не сводима к совокупности акустических свойств знаковой системы» или «языковой знак не сводим к произвольным отношениям означаемого и означающего». К примеру, Дж. Марголис и С. Лоуренс понимают элементы языка как эмерджентно-культурные объекты, условно воплощенные в физическом измерении [6]. То есть семантико-прагматическая природа языкового знака может рассматриваться как связующее звено между ментальными состояниями, феноменальными суждениями (самоаттестацией) и ментальной каузацией.

На первый взгляд фундаментальное отличие эмерджентности языка от эмерджентности сознания состоит в следующем: содержание языковой деятельности - результат извлечения номинативных правил из коммуникации, в то время как субъективный опыт наличия сознания просто присущ человеческому бытию.

В данной статье термин «эмерджентный» мы будем применять к ментальным состояниям сознания и семантическим свойствам языка и понимать его в динамическом ключе в духе П. Хоппера как «продолжающийся процесс структуризации», как «продолжающееся движение в сторону структуры», статическая модель которой как бы «откладывается на потом» [7]. П. Хоппер создал теорию эмерджентной грамматики, исходя из работ Н. Хомского, но развил их в противоположном направлении: от элементарных структур синтаксиса к морфологии. Данная структуризация представляет собой нечто динамичное, гибкое, изменяемое, подверженное компромиссам относительно правил, сформировавших элементы самой структуры. На наш взгляд, это ключевое свойство сознания (множественная нечеткая интерпретация) нашло свое отражение в семантике и прагматике языкового знака. Референциальная интерпретация развивается метафорически, «уводя в сторону» от семантиче- 
ского ядра и порождая множество новых контекстов. Важнейшую роль здесь играет телесная реализация сознания как на уровне когнитивно-информационных процессов мозга, так и на уровне морфологической воплощенности (embodied mind).

Эмерджентность как объединяющее структурно-функциональное свойство языка и сознания, возможно, разрешает как психофизическую проблему так и проблемы онтологии знака.

Эмерджентизм в философии сознания имеет довольно долгую историю. В наши задачи не входит подробное рассмотрение всех этапов формирования данного направления. Укажем лишь на то, что первые идеи эмерджентизма берут свое начало в работах Дж. С. Милля и далее развиваются в британской философской традиции до середины XX в. (С. Александэр, С.Л. Морган, С.Д. Броад и др.) [8]. К основным компонентам эмерджентного видения проблемы сознания относятся:

Натурализм. При этом важно отметить антиредукционизм как основную черту данного вида натурализма.

Новизна системных свойств.

Иерархичная структура и уровни существования. Как и предыдущий, данный компонент позаимствован из Теории сложных систем.

Синхронический и диахронический виды эмерджентизма. Диахронический эмерджентизм утверждает, что при идентичных состояниях начальных условий порождаются идентичные структурные следствия. Синхронический эмерджентизм утверждает, что свойства системы результируются из свойств и порядка структурных компонентов, но не сводятся к ним. Синхронический эмерджентизм в философии сознания сегодня заменяется термином «супервентность» (по Д. Чалмерсу - отношения между множествами свойств).

Hесводимость (irreducibility). Данный компонент эмерджентности является центральным и состоит из двух критериев:

Системные свойства являются несводимыми, (1) если они не анализируемы на уровне поведения системы, (2) если специфическое поведение компонентов системы, из которых «рождаются» системные свойства, не следует из поведения в изоляции или на более простых уровнях системы [9. Р. 34].

Непредсказуемость. Свойства системы могут быть непредсказуемы по трем критериям:

Системные свойства не предсказуемы в принципе до их первого проявления, (1) если они не сводимы к множеству свойств нижнего уровня, (2) если структура, устанавливающая системные свойства, сама непредсказуема [10. P. 54].

Нисходящая каузаџия (downward causation). Принципы причинности внутри системы могут интерпретироваться двояко: либо система, обладающая эмерджентными свойствами, каузально влияет на поведение своих структурных компонентов; либо на компоненты системы влияют сами эмерджентные свойства [10. Р. 58]. Проблема нисходящей каузации напрямую затрагивает проблему ментальной каузации, в которой формулируется традиционный для философии вопрос: как ментальные состояния могут служить причиной физических процессов? 
В контексте поставленных проблем особый интерес вызывают представители интенционального репрезентативизма (Г. Харман, В. Лайкан, Ф. Дретске, М. Тай, Т. Крейн). В данном направлении квалиа понимаются как свойства самого сознательного опыта, а не как свойства чувственных данных. Если квалиа понимать как содержание некоего убеждения, то тогда возможны функциональные описания. Данной группе философов оппонируют представители квалитативного феноменализма (Н. Блок, Т. Нагель, Дж. Левин, К. МакГинн, Ф. Джексон, Д. Чалмерс), утверждающие, что квалиа суть свойства ментальных состояний субъекта, которые «невыразимы, имманентны, приватны, схватываются в сознании прямым и непосредственным образом» [11. P. 385].

Мы полагаем, что связующим звеном между противоречиями этих двух контактных парадигм может выступить специфичная онтология языкового знака, который обладает как репрезентативными, интенциональными, так и феноменальными свойствами. Важно и то, что план языкового выражения имеет корреляты на уровне мозговых функций. Обратимся к оригинальному тексту статьи Д. Деннета. Четвертый пункт характеристик ментальных состояний субъекта описывается пассивной грамматической формой: «Directly or immediately apprehensible in consciousness» [11. Р. 385]. То есть состояния не схватываются сознанием, а схватываются в сознании. Агентом выступает не сознание как таковое, а некоторые имманентные принципы схватывания. На наш взгляд, именно языковая семантика позволяет «реставрировать» оттенки индивидуального сознательного опыта. Итак, при любом из подходов ментальные состояния можно понимать как эмерджентные свойства, так как они не сводимы ни к физическим, ни к функциональным компонентам.

Если мы принимаем позицию эмерджентизма, то сталкиваемся с проблемой ментальной каузации. Проблема ментальной каузации связана с причинным основанием действий. Если принять концепцию физической каузальной замкнутости, то мы вновь возвращаемся к редукционистским моделям. Может ли все многообразие ментальных состояний выводиться из физических состояний носителя сознания? И наоборот, как нематериальные убеждения, желания и верования способны конвертироваться в некие нейронные структуры? Вопрос остается открытым.

Известен аргумент от супервентности Дж. Кима, который последовательно обосновывает невозможность ментальной каузации. Суть аргумента сводится к опровержению психофизической супервентности. Сам аргумент состоит из трех положений:

Каузальная закрытость физической области. Если физическое событие 'e' имеет причину во времени 't', то это будет причина физическая во времени ' $\mathrm{t}$ '.

Принцип каузального исключения. Если событие 'е' имеет достаточную причину 'c' во времени ' $t$ ', то никакое событие во времени 't, отличное от 'c', не может быть причиной 'c'.

Принции детерминативного/генеративного исключения. Если существование некоторого события 'e' или установление свойств 'P' вызвано или определено событием 'c' - каузально или иным способом, тогда 'e' не вызвано 
и не определено никаким событием, отличным или полностью независимым от события 'c' [12].

Впоследствии развернулась бурная дискуссия вокруг аргумента от супервентности Дж. Кима, в рамках которой было сформулировано несколько ценных для нашего подхода идей.

Мы не будем здесь приводить детальные контраргументы доказательствам Дж. Кима [см. 9. С. 74-76], укажем лишь на то, что в заключительном абзаце своей статьи Дж. Ким сам приходит к выводу о том, что можно сохранить непротиворечивость нисходящей каузации, рассмотрев ее в концептуальном ключе: «Это возможно, если мы понимаем иерархию отношений как концепты или описания, или как уровни нашего рапрезентационного аппарата, нежели как уровни свойств и феноменов реального мира. Мы можем говорить о нисходящей каузации, когда причина описана в терминах высокоуровневых концептов или высокоуровневого языка» [12. Р. 33].

Таким образом, семантические принципы концептуализации и парадоксальная онтологическая природа языкового знака, на наш взгляд, способны преодолеть трудность ментальной каузации и психофизической супервентности. Более детально данное положение будет рассмотрено ниже.

\section{2. Эмерджентные свойства языковых процессов}

Далее рассмотрим эмерджентистские тенденции в языковых теориях. Ocновная задача состоит в поиске точек соприкосновения эмерджентных подходов в философии сознания и эмереджентизма в языковых теориях.

Принцип эмерджентности свойств системы во второй половине XX столетия экстраполировался из естественных наук в науки о языке. В первую очередь стоит отметить, что эволюционный натурализм в лингвистике привел к тому, что исследователи стали применять определения самоорганизующихся систем к уровням структурной организации языка (фонетика, морфология, синтаксис). При этом в лингвистическом эмерджентизме наблюдаются тенденции, схожие с процессами в философии сознания. Исследователи пытаются ответить на вопросы: как формальные структуры языка возникают (emerge) из взаимодействия социальных паттернов? как структура паттернов связана с общими аспектами когнитивной системы?

В языковых теориях термин «emergence» используется чаще не в значении эмердежнтности свойств системы, а в прямом значении - как «возникновение», «появление», например в работах по глоттогенезу.

Зарождение языка в рамках эволюционизма выглядит как реализация эмерджентных свойств живых систем. К примеру, в теории происхождения языка существует так называемая модель «Внешнего разума» (The Extended Mind Model of the Origin of Language), в которой человеческая речь понимается как внезапно проявившийся механизм для конвертации перцепта (объекта перцепции) в концепт. Далее приводятся классические компоненты когнитивной деятельности древних гоминид, из которых мог появиться язык:

- Мануальная артикуляция (инструментальная деятельность).

- Социальное взаимодействие.

- Довербальная просодическая и жестовая коммуникация [13. Р. 5]. 
В итоге мы видим, что западные исследователи приходят к идее примата культурной эволюции над генетической, по сути, повторяя выводы культурно-исторического подхода Л.С. Выготского и всей советской психологической школы. Разум имеет внешнее выражение и внешние «блоки памяти», благодаря культурным концептам и коммуникации. Согласно теории «Внешнего разума», существуют базовые уровни культурных универсалий, обладающих языковой природой.

Таблийа 1. Культурные универсалии по Д. Брауну [14]

\begin{tabular}{|c|c|}
\hline $\begin{array}{l}\text { - существительные и глаголы, } \\
\text { - пассивная форма, } \\
\text { - выделение (маркирование), } \\
\text { - специальная речь особых случаев, } \\
\text { - нарративы, } \\
\text { - поэзия с приблизительной паузой через } \\
\text { каждые три секунды, } \\
\text { - фигуральная речь, } \\
\text { - метафора, } \\
\text { - метонимия, } \\
\text { - ономатоэпия, } \\
\text { - категория рода, } \\
\text { - временная длительность, } \\
\text { единицы времени (дни, месяцы, времена года) }\end{array}$ & 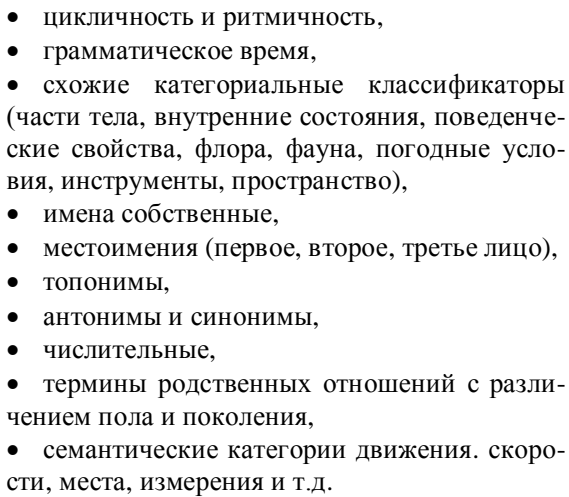 \\
\hline
\end{tabular}

Также в данной теории обосновывается идея меметической культурной трансляции в формы человеческого поведения. Идея культурного мема (как вируса для сознания) активно продвигалась Д. Деннетом в философии сознания. В обоих случаях ментальные состояния концептуально сформированы «культурными вирусами». Язык лишь протоколирует способы взаимодействия индивидуального нарратива с коммуникативной средой.

Если упростить и объединить культурно-историческую теорию глоттогенеза с идеей культурных мемов, то получается, что индивидуальное сознание есть результат коллективного творчества. И вся языковая концептуальная система - не что иное, как прототипическая реализация культуры через индивидуальный опыт существования. Языковая эмерджентность представляет лишь очередной виток эволюции: язык, сознание, культура, технологии - однородные явления, направленные на эффективное решение эволюционных задач. К особым формам лингвистического экстернализма можно отнести работы по интеракциональной семантике, в которых остро ставится вопрос об интерсубъективности и об интенциональном распределении (sharing) [15].

Перечисленные работы характеризуются тем, что в них эволюционное становление (emergence) языка выводится из когнитивно-семантических процессов, обладающих ясными прагматическими свойствами. То есть язык и сознание становятся побочным эффектом от реализации коммуникативных стратегий $[16,17]$. Обозначим условно это направление в рамках лингвистического эмерджентизма как семантико-прагматическое.

В качестве методологической альтернативы можно представить так называемое системное направление эмерджентизма, где сам принцип структурной организации языковой системы описывается как нечто большее, чем сово- 
купность элементов. Известен синтаксический, морфологический, фонологический виды эмерджентизма.

В синтаксисе английского языка существует особый принцип порядковых ограничений, вытекающих из эпистемических модальностей: временная форма и порядок членов предложения напрямую зависят от общего содержания пропозиции. В морфологии известны принципы диахронического эмерджентизма: когда в процессе становления детской речи или при формировании пиджина морфемные деривации закрепляются в коммуникативных циклах. К примеру, причина употребления маркеров прошедшего времени лежит вне правил грамматики. Временная модальность - это свойство опыта, требующего правдоподобного расширения (plausible extension) в языке [18. P. 99-100].

Некоторые эмерджентистские теории в лингвистике обладают специфичными чертами. Например, для Б. Мак-Уинни важна не выводимость высокоуровневых паттернов из низкоуровневых, а отсутствие побуждающих правил. То есть в зарождении свойств языковой системы каузация элиминируется: «Мы должны видеть, каким образом языковое поведение в некоторой целевой области возникает из ограничений, которые выводятся из некоторой связанной с нею внешней области. Например, <..> каким образом фонологические структуры возникают из физиологических ограничений речевого аппарата» [19. Цит. по 20].

Многозначность термина «emergence» сказывается и на содержании методологических подходов. В одних случаях свойства системы $\mathrm{S}$ являются логическими и естественными последствиями некоторых условий Р. В других $-\mathrm{S}$ неожиданно возникает при $\mathrm{P}$, но не по причине $\mathrm{P}$.

При этом системный подход значительно шире, чем чисто синтаксический или морфологический виды эмерджентизма. Язык понимается здесь как иерархическая комплексная адаптивная система. Здесь так же, как и в семантико-прагматическом подходе, язык, познание и сознание неразрывны, только связь эта обнаруживается в грамматических категориях языка.

Так же, как сознание, язык не сводим к нейрофизиологическим процессам. При этом исследования физических процессов позволяют частично установить хотя бы первичную корреляцию между структурно-семантическими компонентами языка, биологической природой мозга и принципами социального взаимодействия языковых субъектов. Понимание языка как комплексной адаптивной системы, наделенной эмерджентными свойствами (как каузативными, так и окказиональными), позволяет рассмотреть в синтетическом единстве соссюровскую, гумбольдтианскую и когнитивно-прагматическую онтологические модели. Динамические структуры языка и сознания допускают единую онтологию для значения и смысла, денотативных и коннотативных свойств, интернализма и экстернализма, синтаксиса и семантики, компьютационизма и психологизма, знания и коммуникации, семантики и онтологии.

Именно в комплексном системном подходе в наиболее очевидном виде проявляются общие ключевые черты в философских исследованиях языка и сознания. Далее перечислим свойства языка как эмерджентной комплексной адаптивной системы. За основу приведенных характеристик взяты положения из работы Н. Эллиса и Д. Ларсен-Фриман «Язык - это комплексная адаптив- 
ная система» [21. Р. 14-18]. (Приведенные характеристики в той или иной форме имеют место и в философских теориях сознания).

Распределенный контроль и коллективное закрепление. Язык существует в двух измерениях: как индивидуальный идиолект и как коллективная практика. Эти два уровня взаимозависимы, так как идиолект формируется в процессе социальных языковых практик, и наоборот, социальный дискурс - это эмерджентный феномен совокупности частных идиолектов.

Внутренняя разнородность. Несмотря на следование правилам как в синтаксисе, так и в социальной прагматике, частный язык - это результат уникального речеповеденческого опыта. Это своего рода постоянное нарушение норм в частном высказывании, из которых на уровне коммуникации рождаются правила, нормы, каноны.

Постоянная динамика. Индивидуальный язык и общий язык находятся в постоянном процессе реорганизации и изменения. Структурный дизайн языка предрасположен к адаптивным изменениям, зависящим от вызова социальной среды.

Адаптация через расширение и факторную конкуренциию. Комплексная адаптивная система языка стремится расширить сферы своего влияния, постоянно делая «запросы» в среду. Множество факторов влияет на способы употребления языковых выражений, как бы проводя естественный отбор по релевантности и функциональности языкового поведения.

Нелинейность и фазовые переходыл. В комплексных системах незначительные изменения в количественных параметрах зачастую приводят к фундаментальным сдвигам качественных отношений. В теории языка известен процесс «лексического рывка» (lexical spurt) - количественного роста лексики, после которого неизбежно происходит развитие усложненных грамматических форм.

Чувствительность $\kappa$ сетевым структурам. Внутренняя структура и связность комплексной системы могут сильно влиять на динамические процессы. Социальная языковая практика носит неслучайный характер: сетевая структура социального взаимодействия вызывает изменения во внутренней системе частного языка.

Локальные изменения. Если язык понимать как социальный интерфейс, производный от намерений, внимания, имитации, последовательного обучения, категоризации, концептуальной кластеризации - всего, что реализуется в когнитивных процедурах мозга, то можно утверждать, что локальные процедуры на уровне материи мозга суть причины развития социальной коммуникации. Это утверждение справедливо как для теории глоттогенеза, так и для теории языкового обучения. Сложность мозговых процессов рождает сложность коммуникации и затем сложность социальных отношений. В итоге социальные отношения транслируют новые задачи и контексты для новых локальных изменений в мозге.

Итак, из представленных положений относительно эмерджентных свойств языка и сознания вытекают важные следствия.

Во-первых, принцип эмерджентности позволяет «ослабить» методологическое напряжение объяснительного разрыва в онтологических вопросах языка и сознания. В эмерджентном подходе можно избежать линейной нис- 
ходящей каузации и редуктивного физикализма. При этом квалитативный эмерджентизм можно представить в терминах концептуальных семантических процессов.

Во-вторых, в современных исследованиях вновь приобретают значимость представления о социально-коммуникативной природе сознания. Мы видим, что язык, сознание, культура представляются как взаимодополняющие элементы эволюционного развития человека. Эмерджентизм позволяет выйти за пределы противопоставления языка как системы и как деятельности. На наш взгляд, особой ценностью обладает мысль о том, что эмерджентные свойства языка и сознания - это результат ограничений, накладываемых различными онтологическими областями: структурой мозга, принципами когнитивной организации деятельности, социальными отношениями, разновидностями интеракциональных контекстов и т.д.

В-третьих, в эмерджентном подходе находят объяснения как субстратные, так и функциональные свойства отношения мозга и сознания. Языковая семантика существует потому, что процессы мозга «не идут в темноте». Феномены квалитативного опыта организованы особым образом: существует целая иерархия феноменальных суждений, удостоверяющих связь семантики и онтологии. При этом не имеет значения, идет ли речь о чувственно воспринимаемом мире или о воображаемом мире. По-видимому, «зазор» между ментальным содержанием и физическими причинами этих содержаний заполняется неким метауровнем, на котором реализуются взаимозависимые отношения «внешнего» и «внутреннего» сознания, языка и речи, денотации и коннотации. Именно на этом уровне накладываются ограничения из множества онтологических областей.

\section{Лuтература}

1. Block N. Anti-Reductionism Slaps Back // Philosophical perspectives / James E. Tomberlin, John Hawthorne. Atascadero, Calif.: Ridgeview Publ. Co., 1997. P. 107-133.

2. Nagel T. Reductionism and Antireductionism // The limits of reductionism in biology / Gregory Bock, Jamie Goode. Chichester, New York: J. Wiley, 1998. P. 3-14.

3. Серл Д. Р. Открывая сознание заново. М.: Идея-пресс, 2002. 256 с.

4. Фролов К. Г. Аналитика эмерджентности в контексте проблемы сознания // Философия науки. 2015. Т. 64, № 1. С. 79.

5. Нагель T. Мыслимость невозможного и проблема духа и тела // Вопросы философии. 2001. № 8. C. 101-112.

6. Margolis E., Laurence S. Concepts and Cognitive Science // Concepts. Core readings / Eric Margolis, Stephen Laurence. Cambridge, Mass.: MIT Press, 1999. P. 9.

7. Hopper P. Emergent Grammar // Annual Meeting of the Berkeley Linguistics Society. 1987. Vol. 13. P. 139-157.

8. McLaughlin B.P. The Rise and Fall of British Emergentism // Emergence or Reduction? / Ansgar Beckermann, Hans Flohr, Jaegwon Kim. Berlin, New York: De Gruyter, 1992. P. 49-93.

9. Eronen M. Emergence in the philosophy of mind: Master's Thesis / Sami Pihlström, University of Helsinki. Helsinki, November, 2004. 83 p.

10. Stephan A. Varieties of Emergentism // Evolution and Cognition. 1999. T. 5, № 1. P. 49-59.

11. Dennett D. C. Quining Qualia // Consciousness in contemporary science / A. J. Marcel, E. Bisiach. Oxford, New York: Clarendon Press; Oxford University Press, 1988. P. 381-414.

12. Kim J. Making Sense of Emergence // Philosophical Studies. 1999. T. 95. C. 3-36.

13. Logan R.K. The extended mind. Toronto, Buffalo: University of Toronto Press, 2007: Toronto studies in semiotics and communication. $320 \mathrm{p}$.

14. Brown D.E. Human universals. New York: Mcgraw-Hill, 1991. 220 p. 
15. Gärdenfors $P$. The evolution of semantics: sharing conceptual domains // The evolutionary emergence of language / Rudolf Botha, Martin Everaert: Oxford Univ. Press, 2013. P. 139-159.

16. Semantic structures, communicative strategies and the emergence of language / Schouwstra M. Utrecht: LOT, 2012. T. 312: International series. 212 c.

17. Knight C., Studdert-Kennedy M., Hurford J.R. CambridgeThe Evolutionary emergence of language. New York: Cambridge University Press, 2000. 426 p.

18. Fortuny J. The emergence of order in syntax. Amsterdam, Philadelphia: John Benjamins Pub., 2008. Vol. 119: Linguistik aktuell. Linguistics today. 210 p.

19. MacWhinney B. Emergentist approaches to language // Frequency and the emergence of linguistic structure / Joan L. Bybee, Paul J. Hopper. Amsterdam, [Great Britain]: J. Benjamins, 2001. P. 449-471.

20. Даль Э. Возникновение и сохранение языковой сложности. М.: Издательство ЛКИ, $2009.560 \mathrm{c}$.

21. Ellis N.C. Diane Larsen-Freeman, Language Is a Complex Adaptive System: Position Paper // Language as a complex adaptive system / Nick C. Ellis, Diane Larsen-Freeman. Chichester, West Sussex, U.K., Malden, MA: Wiley-Blackwell, 2009. P. 1-26.

Baryshnikov Pavel N. Pyatigorsk State Linguistic University (Pyatigorsk, Russian Federation)

DOI: $10.17223 / 1998863 X / 34 / 2$

EMERGENT PROPERTIES OF LANGUAGE PROCESSES IN THE MIND

Keywords: emergentism, functional properties, elementary structures, mental causation

In this paper, we shall cover the theoretical and methodological fundamentals of emergentism in contemporary philosophy of mind and linguistics. The main purpose is to pinpoint the benefits of emergent models in the context of non-reductive functionalism, the theory of syntactic complexity and conceptual semantics. In our view, the dynamic model of the structuring process of elementary components allows associate the mind-body problem of consciousness with the problem of syntactic complexity and properties of non-strict semantics. The emergent structuring is dynamic, flexible, variable, and prone to compromise on the rules that have shaped the structural elements. In our view, this key feature of consciousness (multiple vague interpretation) is reflected in the semantics and pragmatics of the language sign. We proceed from the statement that the "challenging problem" of consciousness, the result of a specific ontology of the language sign. The semantic and pragmatic nature of a linguistic sign may be considered a link between mental states, phenomenal judgments (self-assessment), and mental causation. The article substantiates the idea that the emergent approach may help avoiding the linear downward causation and reductive physicalism, while the qualitative emergentism may be represented in terms of conceptual semantic processes. The emergent properties of language and consciousness result from the constraints imposed by different ontological areas: brain structure, principles of organization of cognitive activity, social relations, varieties of interactional contexts, etc. The emergence approach explains both substrate and functional properties of the relation between the brain and consciousness. Language semantics exists because the brain processes "do not happen in the dark." The phenomena of the qualitative experience are organized in a specific way: there is a whole hierarchy of phenomenal judgment supporting the relation between semantics and ontology. Yet, it does not matter whether it is about the tangible or imaginary world. Apparently, the "gap" between the mental component and the physical causes of these contents is filled with a certain meta-level where the interdependent relationship between the "external" and "internal" consciousness, speech and language, denotation and connotation are implemented. It is at this level that the restrictions of the numerous ontological areas are imposed.

\section{References}

1. Block, N. (1997) Anti-Reductionism Slaps Back. In: Tomberlin, J.E. \& Hawthorne, J. Philosophical perspectives Atascadero: Ridgeview Publ. Co. pp. 107-133.

2. Nagel, T. (1998) Reductionism and Antireductionism. In: Bock, G. \& Goode, J. The limits of reductionism in biology. Chichester, New York: J. Wiley. pp. 3-14.

3. Searle, D.R. (2002) Otkryvaya soznanie zanovo [Rediscovery of the Mind]. Translated from English by A.F. Gryaznov. Moscow: Ideya-press.

4. Frolov, K.G. (2015) Analitika emerdzhentnosti v kontekste problemy soznaniya [Research of emergence in the context of the consciousness]. Filosofiya nauki. 64(1). p. 79. DOI: 10.15372/PS20150106 
5. Nagel, T. (2001) Myslimost' nevozmozhnogo i problema dukha i tela [The conceivable of the impossible and the problem of mind and body]. Voprosy filosofii. 8. pp. 101-112.

6. Margolis, E. \& Laurence, S. (1999) Concepts. Core readings. Cambridge, Mass.: MIT Press. p. 9.

7. Hopper, P. (1987) Emergent Grammar. Annual Meeting of the Berkeley Linguistics Society. 13. pp. 139-157.

8. MsLaughlin, B.P. (1992) The Rise and Fall of British Emergentism. In: Beckermann, A., Flohr, H. \& Kim, J. Emergence or Reduction? Berlin, New York: De Gruyter. pp. 49-93.

9. Eronen, M. (2004) Emergence in the philosophy of mind. Master's Thesis. Helsinki: University of Helsinki.

10. Stephan, A. (1999) Varieties of Emergentism. Evolution and Cognition. 5(1). pp. 49-59.

11. Dennett, D.C. (1988) Quining Qualia. In: Marcel, A.J. \& Bisiach, E. Consciousness in contemporary science. Oxford, New York: Clarendon Press; Oxford University Press. pp. 381-414.

12. Kim, J. (1999) Making Sense of Emergence. Philosophical Studies. 95. pp. 3-36. DOI: 10.1093/acprof:oso/9780199585878.001.0001

13. Logan, R.K. (2007) The extended mind. Toronto, Buffalo: University of Toronto Press.

14. Brown, D.E. (1991) Human universals. New York: Mcgraw-Hill.

15. Gärdenfors, P. (2013) The evolution of semantics: sharing conceptual domains. Botha, R. \& Everaert, M. The evolutionary emergence of language. Oxford Univ. Press. pp. 139-159.

16. Schouwstra, M. Semantic structures, communicative strategies and the emergence of language. Vol. 312. Utrecht: LOT.

17. Knight, C., Studdert-Kennedy, M., Hurford, J.R. (eds) (2000) The Evolutionary emergence of language. New York: Cambridge University Press.

18. Fortuny, J. (2008) The emergence of order in syntax. Vol. 119. Amsterdam, Philadelphia: John Benjamins Pub.

19. MacWhinney, B. (2001) Emergentist approaches to language. In: Bybee, J.L. \& Hopper, P.J. (eds) Frequency and the emergence of linguistic structure. Amsterdam: J. Benjamins. pp. 449-471.

20. Dahl, E. (2009) Vozniknovenie i sokhranenie yazykovoy slozhnosti [Emergence and preservation of linguistic complexity]. Moscow: LKI.

21. Ellis, N.C. et al. (2009) Language Is a Complex Adaptive System: Position Paper. In: Ellis, N.C. \& Larsen-Freeman, D. (eds) Language as a complex adaptive system. Chichester, West Sussex, U.K., Malden, MA: Wiley-Blackwell. pp. 1-26. 